\title{
Mediastinitis complicating a percutaneous endoscopic gastrostomy:
}

\section{a case report}

\author{
Kalliopi Papakonstantinou ${ }^{1}$, Athanasios Karagiannis ${ }^{1}$, Maria Tsirantonaki*1, \\ Anastasios Konstantinidis ${ }^{2}$, Spiros Spirou ${ }^{1}$, Ion Skottis ${ }^{3}$ and \\ Andreas Karabinis ${ }^{1}$
}

\begin{abstract}
Address: ${ }^{1}$ Intensive Care Unit of Athens General Hospital, Athens, Greece, ${ }^{2}$ Endoscopic Department of Athens General Hospital, Athens, Greece and ${ }^{3}$ First Thoracic Surgery Department of Athens Chest Diseases Hospital "Sotiria", Athens, Greece

Email: Kalliopi Papakonstantinou - akarab@forthnet.gr; Athanasios Karagiannis - cava@otenet.gr; Maria Tsirantonaki* - saitanis@aua.gr; Anastasios Konstantinidis - akarab@forthnet.gr; Spiros Spirou - akarab@forthnet.gr; Ion Skottis - akarab@forthnet.gr; Andreas Karabinis - akarab@forthnet.gr

* Corresponding author
\end{abstract}

This article is available from: http://www.biomedcentral.com/I47I-230X/3/II

(C) 2003 Papakonstantinou et al; licensee BioMed Central Ltd. This is an Open Access article: verbatim copying and redistribution of this article are permitted in all media for any purpose, provided this notice is preserved along with the article's original URL.

\begin{abstract}
Background: Since its introduction in the early 1980s, percutaneous endoscopic gastrostomy has become the most popular method for performing a gastrostomy for long-term enteral feeding. It has been associated, however, with a lot of minor and major complications.

Case presentation: A case of mediastinitis with concominant sepsis caused by a masked esophageal perforation after percutaneous endoscopic gastrostomy in a multi-traumatized, braininjured patient is presented. Ten - fourteen days after the procedure, the patient became febrile and gradually septic with tenderness of the sternum and upper abdomen. Computerized tomography of the thorax revealed mediastinitis. An urgent left thoracotomy and laparotomy were performed for drainage of the mediastinum, removal of the gastrostomy and insertion of a jejunostomy tube. The patient improved soon after the surgery. He was successfully weaned off the ventilator and was discharged from the Intensive Care Unit.
\end{abstract}

Conclusion: Perforating mediastinitis is a rare but potentially lethal complication of percutaneous endoscopic gastrostomy. When diagnosed and properly treated it may have a favourable outcome.

\section{Background}

Since its clinical introduction in 1980, percutaneous endoscopic gastrostomy (PEG) has become a widespread endoscopic technique for inserting feeding tube for longterm enteral nutrition. Although much has been reported about its complications, perforating mediastinitis has not been mentioned in the recent literature.
Herein a case of mediastinitis complicating PEG in a multi-traumatized, brain-injured patient is presented. Mediastinitis is a rare but potentially lethal complication of PEG. In the sedated or comatose patient the diagnosis may be delayed. High clinical suspicion and early CT scan of the thorax are essential for accurate diagnosis, appropriate management and favourable outcome. 


\section{Case presentation}

A 33-year old male was transferred to the Intensive Care Unit (ICU) from the Emergency Room because of multiple trauma following a motor vehicle accident. He had suffered severe brain-injury (brain contusions, edema, subarachnoid haemorrhage, skull fractures) resulting to coma (Glasgow Coma Scale (GCS): 5/15), facial fractures, lung contusions, bilateral haemothorax and an open fracture of the tibia.

The patient was intubated, sedated and mechanically ventilated. Pleural drainage, percutaneous dilational tracheostomy and external fixation of the tibia were performed uneventfully. One month later he was successfully weaned off the ventilator but, because he was not alert enough (GCS: 9/15), it was decided to leave the tracheostomy tube in place and perform a PEG.

The endoscopists had difficulties in the whole PEG procedure due to the patient's obesity. Although endoscopically the oesophagus and the stomach were normal, the translumination of the abdominal wall was poor and the indentation of the anterior stomach wall was made by external pressure. Three attempts under $45^{\circ}$ angle in 3 different sites with a distance of $1-2 \mathrm{~cm}$ between them were made to puncture the stomach with a longer than usual needle $(15 \mathrm{~cm})$. The gastrostomy tube was inserted using the "pull through" technique, was checked endoscopically and was found to be in place. After the procedure, the patient was sweaty, tachycardic (120 b.p.m) and mildly hypotensive (BP $100 / 70 \mathrm{mmHg}$ ) but he was soon stabilized with infusion of $1000 \mathrm{cc}$ of colloids and an extra dose of analgetic. An abdominal X-ray with contrast did not reveal any leakage. Abdominal ultrasonography detected no pathology and his haemoglobin remained stable. Feeding started next day.

By the $10^{\text {th }}$ postoperative day the patient became febrile $\left(39^{\circ} \mathrm{C}\right)$; blood cultures grew methicillin resistant Staphylococcus aureus (MRSA) and Klebsiella pneumonia (Kl.), so intravenous infusion of teicoplanin and imipenem was started. Because of deterioration of his general condition, mechanical ventilation was started again. The physical examination, chest X-ray, biochemistry and cultures of bronchial secretions and urine were unremarkable. The tip of the gastrostomy tube was checked by endoscopy to be in place. By the $14^{\text {th }}$ postoperative day, tenderness of the lower sternum and upper abdomen was detected. The skin overlying the affected region was normal. A CT scan of the thorax (Figure 1) and abdomen disclosed an extensive inflammation with air in the anterior mediastinum, opacification of the subcutaneous tissue around the entrance of the gastrostomy tube and under the left hemidiaphragm, thickening of the pericardium and bilat-

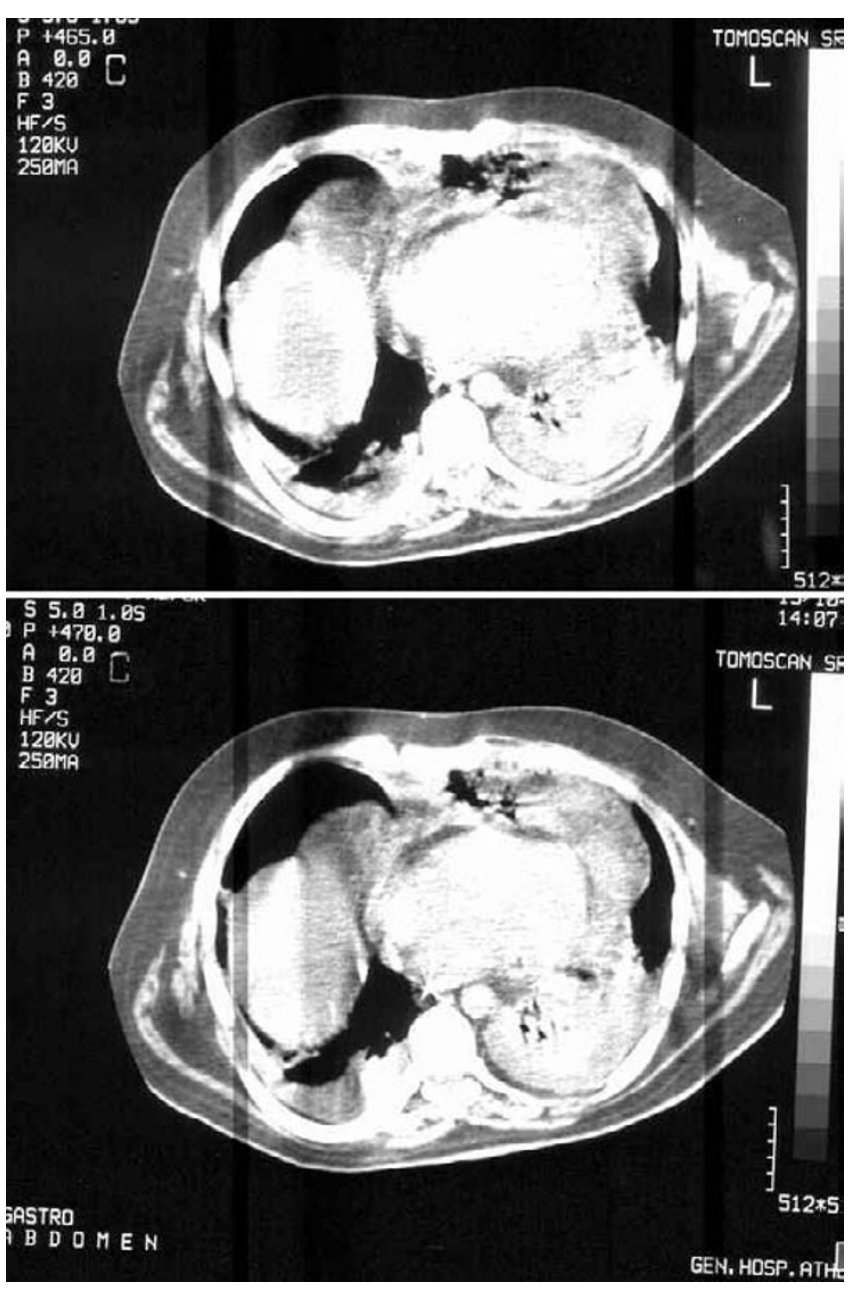

\section{Figure I}

Thorax CT scan showing extensive inflammation with air in the anterior mediastinum.

eral pleural effusions. No leakage of the contrast material in the peritoneal cavity was noticed.

The patient underwent an urgent left lateral-posterior thoracotomy and laparotomy. A small hole of the anterior oesophageal wall at the oesophagogastric junction, covered by the omentum, was found. The surrounding tissues were inflammatory. The gastrostomy tube was found to be dislocated with its tip in the subcutaneous adipose tissue. Wide surgical exploration and drainage of the mediastinum, pericardium, subdiaphragmatic area and pleural cavities were undertaken. The gastrostomy tube was removed and a jejunostomy tube was inserted. Cultures of infected specimens grew MRSA and $\mathrm{Kl}$. 
The postoperative recovery was normal. Gradually, the patient became afebrile and was successfully weaned off the ventilator. He was discharged from the ICU 93 days following his motor-vehicle accident. Six months later, he was still in GCS 9/15 with the tracheostomy and jejunostomy tubes in place.

\section{Discussion}

The traditional indications for PEG [1] are the need for long term nutritional support or gastric decompression $[2,3]$.

Although a lot of major and minor complications have been reported since the PEG was first performed (Table 1), mediastinitis complicating PEG is described for first time in the literature.

Table I: Complications of PEG

I. Due to the endoscopy procedure

- Laryngospasm [4], airway obstruction

- $\quad$ aspiration and pneumonia (4)

- respiratory depression or apnea [5]

- desaturation [5] or respiratory distress and acute respiratory failure

- hypertension [5]

- fracture of the alveolar ridge while attempting to open the mouth [5]

II. Due to the PEG and the gastrostomy tube

- perforation/laceration of the oesophagus or the stomach [4-7]

- $\quad$ transhepatic insertion of the tube [3]

- pneumoperitoneum [8]

- colonic perforation [7]

- subcutaneous emphysema [9]

- retroperitoneal hemorrhage [10]

- aortic perforation [II]

- $\quad$ erosion of the gastric mucosa and bleeding $[4,5,9]$

- hematoma or infection of the abdominal wall [4,7]

- gastrocolic fistula [12]

- colocutaneous fistula [13]

- hypertrophic granulation tissue at the gastrostomy exit [5]

- burried bumper syndrome [14]

- malpositioning of the tube or leakage

- to the subcutaneous tissues $\rightarrow$ cellulitis, myositis, necrotinzing fasciitis [15], subcutaneous abscess [14]

- to the peritoneal cavity $\rightarrow$ peritonitis [5,9,12], intraabdominal abscess [9], sepsis[12].

- migration of the tip of the gastrostomy tube

- to oesophagus (oesophagitis)

- to pylorus (obstruction or perforation of the duodenum) [16]

- migration of the whole PEG tube up to the terminal ileum [17]

- peristomal hernia or stomal prolapse

- accidental pulling out or cutting off the tube close to the skin during home care [5]

- erosion of the tube through the gastric wall

- obstruction of the tube lumen [6]

- hub detachment [18] or damage

- later symptomatic gastroesophageal reflux [7]

- $\quad$ lleus $[4,6]$

III. Due to the mode of feeding

- Diarrhoea $[6,16]$

- nausea

- vomiting

- Dumping syndrome

- Ogilvie's syndrome [4]

- Aspiration pneumonia [19]

- Constipation and meteorism 
In our patient, operation disclosed a small hole of the anterior oesophageal wall at the oesophagogastric junction, covered by the omentum and the gastrostomy tube to be dislocated with its tip in the subcutaneous adipose tissue. Although definite causes or contributory factors of our patient's condition remain unclear, possibly, the repeated attempts to puncture the stomach because of the poor translumination of the anterior abdominal wall and the use of a long needle have resulted in a masked small perforation of the distal oesophagus. The surrounding inflammation was initially well contained perhaps because of the patient's young age, antibiotic coverage and the small size of the perforation. Later, when sepsis emerged, the source of infection, namely mediastinitis, remained clinically obscure in our comatose patient. When the gastrostomy tube was accidentally dislodged, during the everyday nursing care, some food started to leak through the surrounding tissues. As a consequence, the whole inflammation got worse and localizing signs of sepsis became obvious. A following CT scan confirmed the diagnosis. Fortunately, the surgical debridement accompanied by proper antibiotics resulted in full recovery.

According to the literature, obesity is not considered to be an absolute contraindication for PEG any more. The procedure should be spared in patients with gastric ulcers, ascites, sepsis, Crohn's disease with fistulas and serious uncontrolled coagulopathies [17]. Problems may arise when there is a rigid jaw, a high transverse stomach or a megacolon, an oesophageal stricture, or a small gastric remnant due to previous surgery [5]. In any case, the good translumination of the anterior abdominal wall and/or the indentation of the anterior stomach wall by external pressure as seen through the gastroscope are necessary before any attempt to puncture the stomach is made $[2,5,7]$. Long needles (up to $12 \mathrm{~cm}$ ) have been used in the past when there was an increase of the distance between the gastric wall and the anterior abdominal wall due to obesity [5].

Although esophageal perforation is an uncommon complication of PEG, this possibility must be recognized and appropriately treated when it does occur. Timely diagnosis is important to minimize morbidity. Conservative treatment with intravenous antibiotics and avoidance of oral intake may have an excellent outcome. Mediastinitis - a possible outcome of esophageal perforation - has not been reported. A needle esophageal perforation tends to be small and possible rapid closure avoids continued contamination of the mediastinum. Moreover, although our patient was given antibiotics and was fed through gastrostomy, mediastinitis was not prevented. The significant morbidity he experienced further highlights the potential dangers of an esophageal perforation retained for pro- longed periods. Early CT evaluation should be performed to assess esophageal leakage and degree of mediastinitis. Timing and extent of surgical intervention need to be individualized based on this further evaluation and overall patient condition. Accidental removal of the gastrostomy tube is a well known complication of the PEG and may result in peritonitis, intraabdominal abscesses, cellulitis and necrotizing fasciitis of the abdominal wall.

The PEG technique is a reasonably safe procedure, superior to the operative gastrostomy if complication rate, cost and length of hospitalization are all taken into account [18]. Nevertheless there is a wide range of the reported major and minor complications following the PEG procedure in the literature ( $0-32 \%$ or even more) [9]. The 30day mortality rate also varies from $0.3 \%$ up to $26 \%$ in fragile debilitated patients $[2,17]$. These differences may reflect differences in patients' selection criteria. Additionally, some patients may succumb to complications of their underlying disease. An increased risk of death related to PEG has been associated with older age, male gender, diabetes mellitus, acute medical illness, advanced malignancies, low body mass index, malnutrition and mental disorders [20]. The most interesting and unexpected aspect, in our critically ill, comatose patient, was the development of late mediastinitis in the setting of an unrecognized esophageal injury complicating the procedure. This case illustrates one more potentially life-threatening complication of PEG and emphasises that a high index of suspicion of esophageal perforation is needed in critically ill, comatose patient to avoid missing this diagnosis and its possible complications. We should keep in mind that the PEG poses an additional risk of morbidity and mortality when it is performed in critically ill, comatose patients.

\section{Conclusion}

Mediastinitis due to esophageal perforation complicating PEG, although rare, may occur. High clinical suspicion, early diagnosis and appropriate surgical intervention may be life-saving.

\section{Competing Interests}

None declared.

\section{Acknowledgements}

Written consent was obtained from the relatives of the patient for the publication of the patient's details.

\section{References}

I. Gauderer MWL, Ponsky JL and Izant RJ Jr: Gastrostomy without laparotomy: A percutaneous endoscopic technique J Pediatr Surg 1980, 1 5:872-5.

2. American Society for Gastrointestinal Endoscopy: Role of PEG/PEJ in enteral feeding Gastrointest Endosc 1998, 48:699-70 I.

3. Stellato TA and Gauderer MWL: PEG for Gastrointestinal Decompression Ann Surg 1987, 205: I 19-22. 
4. Larson DE, Burton DD, Schroeder KW and DiMagno EP: Percutaneous endoscopic gastrostomy. Indications, success, complications, and mortality in 314 consecutive patients Gastroenterology 1987, 93:48-52.

5. Grant JP: Percutaneous endoscopic gastrostomy. Initial placement by single endoscopic technique and long-term followup Ann Surg 1993, 217 : 168-174.

6. Panos MZ, Reilly H, Moran A, Reilly T, Wallis PJW, Wears R and Chesner IM: Percutaneous endoscopic gastrostomy in a general hospital: prospective evaluation of indications, outcome, and randomised comparison of two tube designs Gut 1994, 35:155|-1556.

7. Beaslay SW, Catto-Smith AG and Davidson PM: How to avoid complication during percutaneous endoscopic gastrostomy J Pediatr Surg 1995, 30:67|-3.

8. Gottfried EB, Plumiser AB and Clair MR: Pneumoperitoneum following percutaneous endoscopic gastrostomy Gastrointest Endosc 1986, 32:397-9.

9. Peteren $\mathrm{TI}$ and Kruse $\mathrm{A}$ : Complications of percutaneous endoscopic gastrostomy Eur J Surg 1997, I 63:35 I-356.

10. Lau G and Lai SH: Fatal retroperitoneal haemorrhage: an unusual complication of percutaneous endoscopic gastrostomy Forensic Sci Int 200I, I I 6:69-75.

II. Robinson SR, Johnston P and Wyeth JW: Aortic perforation due to an impacted percutaneous endoscopic gastrostomy gastric flange Aust N Z J Surg 200 I, 7 I:7I-2.

12. Kimber CP, Khattak IU, Kiely EM and Spitz L: Peritonitis following percutaneous gastrostomy in children: management guidelines Aust N ZJ Surg 1998, 68:268-70.

I3. Yamazaki T, Sakai Y, Hatakeyama K and Hoshiyama Y: Colocutaneous fistula after percutaneous endoscopic gastrostomy in a remnant stomach Surg Endosc 1999, I3(3):280-2.

14. Finocchiaro C, Galletti R, Rovera G, Ferrari A, Todros L, Vuolo A and Balzola F: Percutaneous endoscopic gastrostomy: a long-term follow-up Nutrition 1997, 13:520-3.

15. Korula J and Rice HE: Necrotizing fasciitis and percutaneous endoscopic gastrostomy Gastrointest Endosc 1987, 33:335-6.

16. Hull MA, Rawlings J, Murray FE, Field J, Mclntyre AS, Mahida YR, Hawkey C] and Allison SP: Audit of outcome of long-term enteral nutrition by percutaneous endoscopic gastrostomy Lancet 1993, 341:869-872.

17. Patel B, Fares J, Green J and Spira R: Endoscopic retrieval of a dislodged PEG tube from the terminal ileum [abstract] $\mathrm{Am} \mathrm{J}$ Gastroenterol 200I, S232:AB74I.

18. Moran BJ, Taylor MB and Jonson CD: Percutaneous endoscopic gastrostomy Br J Surg 1990, 77:858-862.

19. Kadakia SC, Sullivan HO and Starnes E: Percutaneous endoscopic gastrostomy or jejunostomy and the incidence of aspiration in 79 patients Am J Surg 1992, 164: I |4-8.

20. Abuksis G, Mor M, Segal N, Shemesh I, Plout S, Sulkes J, Fraser GM and Niv Y: Percutaneous endoscopic gastrostomy: high mortality rates in hospitalized patients Am J Gastroenterol 2000, 95: $128-32$

\section{Pre-publication history}

The pre-publication history for this paper can be accessed here:

http://www.biomedcentral.com/1471-230X/3/11/prepub
Publish with Biomed Central and every scientist can read your work free of charge

"BioMed Central will be the most significant development for disseminating the results of biomedical research in our lifetime. "

Sir Paul Nurse, Cancer Research UK

Your research papers will be:

- available free of charge to the entire biomedical community

- peer reviewed and published immediately upon acceptance

- cited in PubMed and archived on PubMed Central

- yours - you keep the copyright

Submit your manuscript here:

http://www.biomedcentral.com/info/publishing_adv.asp
BioMedcentral 